\title{
Interleukin-11-induced capillary leak syndrome in primary hepatic carcinoma patients with thrombocytopenia
}

\author{
Wang Kai-Feng, Pan Hong-Ming ${ }^{*}$, Lou Hai-Zhou, Shen Li-Rong and Zhu Xi-Yan
}

\begin{abstract}
Background: Capillary leak syndrome (CLS) is a rare condition characterized by recurrent episodes of generalized edema and severe hypotension associated with hypoproteinemia. Interleukin-11 (IL-11) is a promising therapeutic agent for thrombocytopenia. A direct correlation between IL-11 and CLS has never been reported previously, particularly in patients with hepatic carcinoma.
\end{abstract}

Case presentation: We describe two cases of CLS after IL-11 administration in two males with thrombocytopenia. Case 1 was a 46-year-old man with recurrence of hepatic carcinoma who was treated with IL-11 (3 mg per day). After four days of therapy, hypotension and hypoproteinemia were detected. The chest X-ray and B ultrasound of the abdomen showed pleural effusion and ascites. IL-11 was then discontinued, fluid resuscitation was performed, and fresh frozen plasma and packed red blood cells were transfused into this patient. The patient had recovered after 19 days of treatment.

Case 2 was a 66-year-old man who had undergone radiofrequency ablation (RFA) for hepatic carcinoma. He was treated with IL-11 (3 mg per day) for thrombocytopenia. After two days of therapy, this patient complained of dyspnea with bilateral edema of the hands. Laboratory values showed hypoproteinemia. IL-11 was stopped and human albumin was transfused at a rate of $10 \mathrm{~g}$ per day. On the $4^{\text {th }}$ day, fluid resuscitation was performed. The patient had recovered after treatment for two weeks.

Conclusions: The detection of IL-11-induced CLS supports the hypothesis that CLS could be a severe side effect of IL-11 treatment in some patients. These two case reports also demonstrate that patients with hepatic carcinoma who experience this rare form of CLS after treatment with IL-11 seem to respond to a therapeutic regimen that involves hydroxyethyl starch, albumin, and diuretic therapy. Liver cancer patients might be more susceptible to CLS because of poor liver function and hypersplenia. In addition, bleeding after RFA might be a further inducer of CLS.

\section{Background}

Capillary leak syndrome (CLS) is a rare clinical syndrome that was first described in 1960. In the vast majority of cases, it is characterized by acute episodes of generalized edema, hemoconcentration, and hypoproteinemia. The cause of CLS is unknown, and the condition is probably under recognized because of its nonspecific symptoms and signs and high mortality rate. Up to and including 1990, 25 cases of CLS had been analyzed in total worldwide [1]. In 2007, Matsumura et al. reported that approximately 57 cases had been identified in total,

\footnotetext{
* Correspondence: panhongming@tom.com

Department of Oncology, Sir Run Run Shaw Hospital, Medical School, Zhejiang University, 3 Qingchun Dong Street, Hangzhou, China
}

12 of whom died of the disease during follow-up [2]. However, in the same year, Dhir et al. stated that there had been 75 additional reports of CLS since the review published in 1990 [3]. We have found 17 reports in the last 3 years; four of which occurred in infants and none in patients with liver cancer. Therefore, the number of reported cases of this syndrome now totals 117 , and has shown an increasing trend since this syndrome was first recognized. In contrast to the poor survival noted previously, the prognosis of this syndrome now seems to be fair, with a 5 -year survival rate of $70 \%$. Further understanding of this enigmatic syndrome is needed.

Many drugs are known to induce CLS, including interleukin-2 (IL-2) [4], gemcitabine [5], doxorubicin [6], 
granulocyte colony stimulating factor (G-CSF) [7], and interferon [8]. Hsiao et al. described the first case of CLS induced by molecular target medicine in 2010 [9]. Miscellaneous conditions such as carbon monoxide poisoning [10], postpartum state [11], and pustular psoriasis [12] have been also associated with CLS.

To our knowledge a correlation between CLS and IL11 in patients with liver cancer has never been reported. The identification of IL-11-induced CLS is quite important, because it supports the hypothesis that IL-11 is responsible for the pathogenesis of IL-11-related acute hypotension. Given that no effective treatment for CLS has been found so far, CLS can lead to death if the blood pressure is not increased during the initial capillary leak phase. Usually CLS responds successfully to hydroxyethyl starch, albumin, and diuretics.

\section{Case Presentation}

\section{Case 1}

On May $27^{\text {th }} 2008$, a 46-year-old man was admitted to our hospital with hypersplenia after radiofrequency ablation (RFA) for liver cancer. On the day of admission, the blood pressure of the patient was $122 / 76 \mathrm{mmHg}$, heart rate was 72 beats per minute (bpm), respiratory rate was 20 per minute, and oral body temperature was $36.9^{\circ} \mathrm{C}$. The chest computed tomography (CT) scan was normal. Laboratory values were as follows: leukocytes count $3.0 \times 10^{9} / \mathrm{L}$; hemoglobin $12 \mathrm{~g} / \mathrm{dL}$; hematocrit $35.8 \%$; platelet count $48 \times 10^{9} / \mathrm{L}$; albumin $3.2 \mathrm{~g} / \mathrm{dL}$; aspartate aminotransferase (AST) 82 IU/L (normal 5-35 IU/L); alanine aminotransferase (ALT) 51.1 IU/L (normal 5-45 IU/L). Therefore, IL-11 was administered subcutaneously at a dose of $3 \mathrm{mg}$ per day because of thrombocytopenia.

Four days later, the patient felt fullness of the abdomen. His oral body temperature was $39.8^{\circ} \mathrm{C}$, blood pressure was $102 / 61 \mathrm{mmHg}$, and pulse was $118 \mathrm{bpm}$. The breath sounds of the lower right lung were weak. Shifting dullness was detected in the abdomen. Laboratory values were as follows: leukocytes count $4.2 \times 10^{9} / \mathrm{L}$; hemoglobin $11.7 \mathrm{~g} / \mathrm{dL}$; hematocrit 34\%; platelet count $46 \times 10^{9} / \mathrm{L}$. Piperacillin/Tazobactam was infused at a dose of $4.5 \mathrm{~g} \mathrm{q} 8 \mathrm{~h}$ for prophylaxis against infection. Indomethacin was administered against fever. However, the hypotension did not improve. At 21:00 on the same day, the patient complained of dyspnea and fatigue, his blood pressure was $86 / 52 \mathrm{mmHg}$, pulse was $120 \mathrm{bpm}$, and temperature was $40.5^{\circ} \mathrm{C}$. The X-ray of his chest is shown in Figure 1. There were moderate amounts of ascites in the abdomen as shown by B ultrasound (Figure 2). As a consequence, fluid infusion was administered rapidly to this patient. However, the edema deteriorated dramatically and he developed oliguria, but pulmonary edema was not observed. The patient was

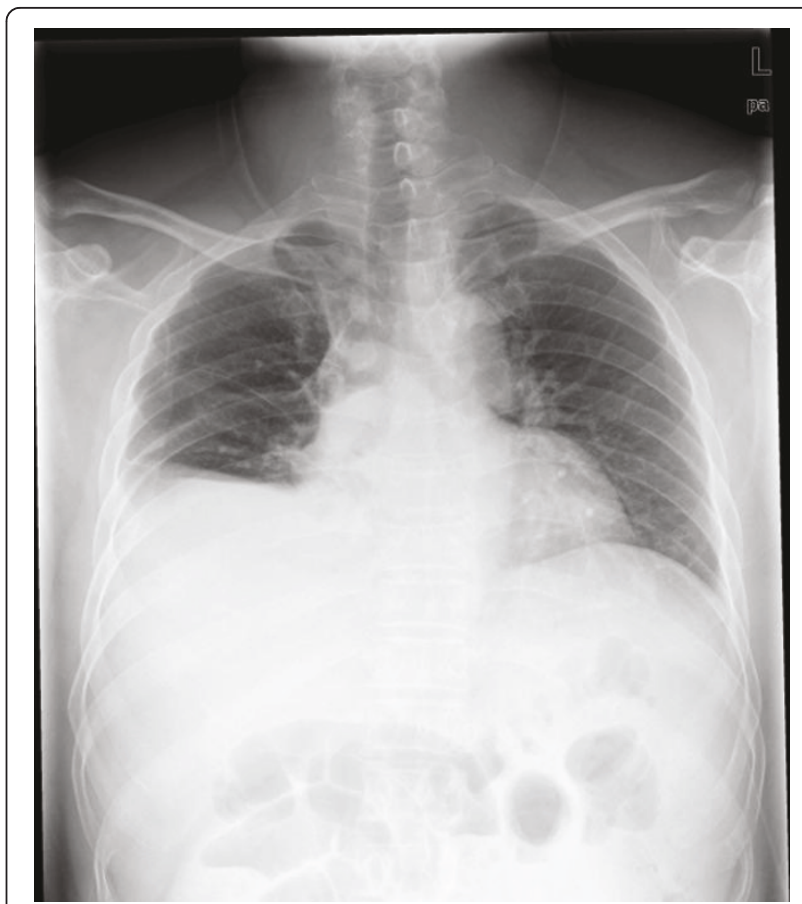

Figure 1 The right diaphragm and costophrenic angle were obscured. There was moderate right pleural effusion in case 1 after treatment with $\mathrm{IL}-11$.

transferred to the ICU department at 23:00, when his blood pressure was $76 / 49 \mathrm{mmHg}$, and pulse was 122 $\mathrm{bpm}$. Fluid resuscitation and the administration of dopamine were initiated. On ICU day 2, the laboratory values were as follows: leukocytes count $7.0 \times 10^{9} / \mathrm{L}$; hemoglobin $7.5 \mathrm{~g} / \mathrm{dL}$; hematocrit $21.7 \%$; platelet count $30 \times 10^{9} /$ L. Serum albumin had decreased to $1.8 \mathrm{~g} / \mathrm{dL}$. Therefore, packed red blood cells (pRBCs) 4.0 units with fresh frozen plasma (FFP) $400 \mathrm{ml}$ were transfused into this patient at 02:00 and infusion of hydroxyethyl starch and albumin was started. On ICU day 3, serum albumin had increased to $2.3 \mathrm{~g} / \mathrm{dL}$. Over the following days, the hypovolemic shock and pleural effusion subsided gradually. However, on ICU day 4, edema of feet, the penis

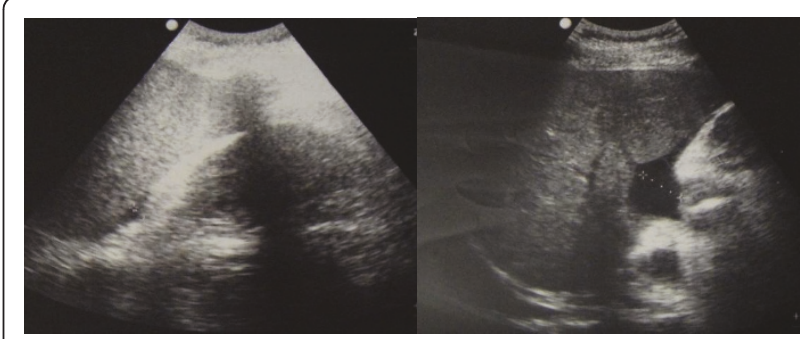

Figure 2 Moderate amounts of ascites were detected in case 1 after treatment with IL-11 by color doppler ultrasound: $2.1 \mathrm{~cm}$ in perihepatic region, $0.8 \mathrm{~cm}$ in perisplenic region, and $2.8 \mathrm{~cm}$ in the right lower abdomen. 


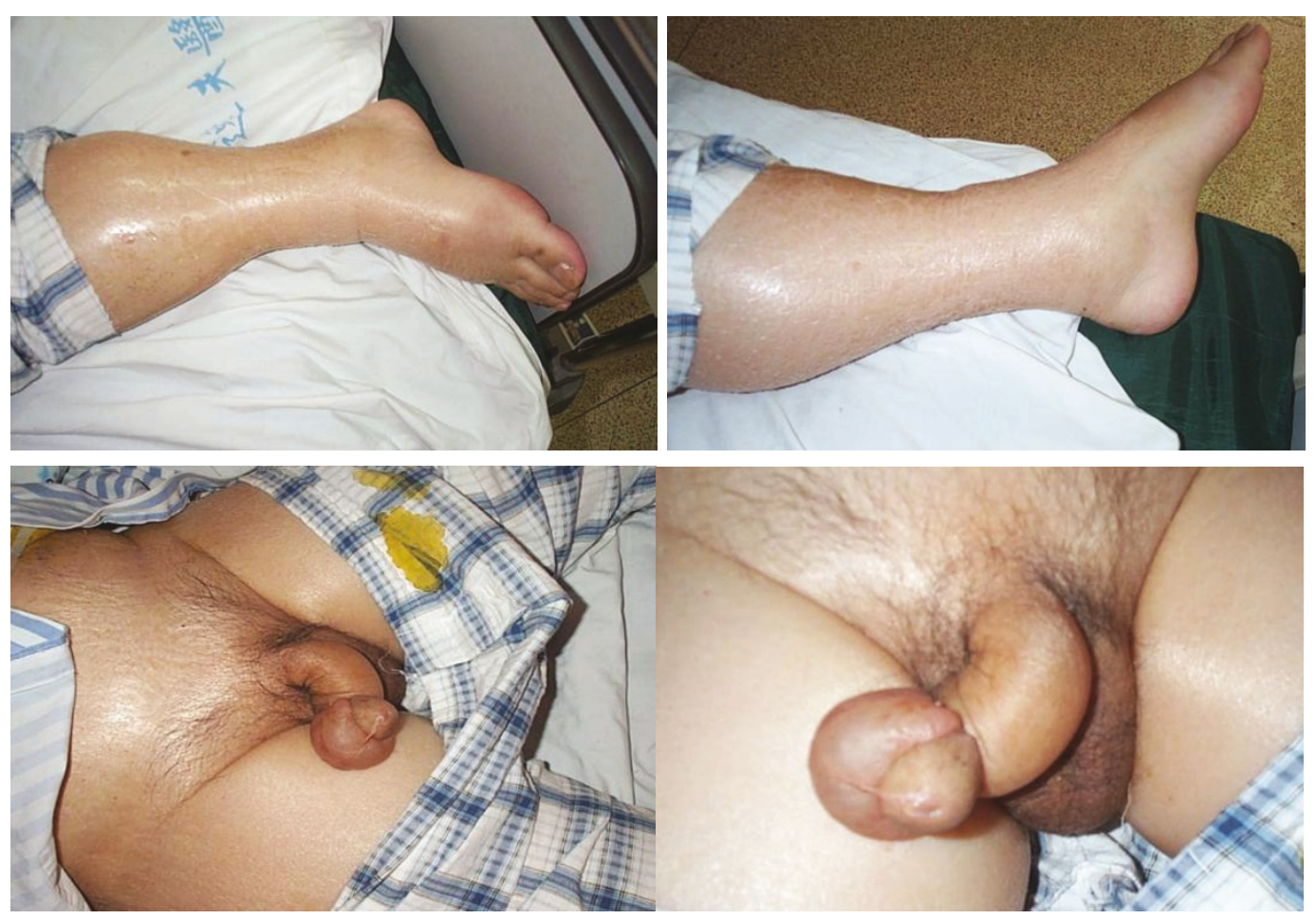

Figure 3 Bilateral lower extremity edema, scrotum edema and penis edema were observed after treatment with IL-11 in case 1.

and scrotum appeared (Figure 3), and the patient was treated with albumin (10 g per day), spironolactone (40 mg per day), and hydrochlorothiazide (25 mg per day). The edema was alleviated gradually. After 19 days of treatment, the patient was discharged. On the day of discharge, the laboratory values were as follows: leukocytes count $5.2 \times 10^{9} / \mathrm{L}$; hemoglobin $11.3 \mathrm{~g} / \mathrm{dL}$; hematocrit $33.3 \%$; platelet count $65 \times 10^{9} / \mathrm{L}$. Serum albumin had increased to $3.1 \mathrm{~g} / \mathrm{dL}$.

\section{Case 2}

On May $24^{\text {th }}$ 2010, a 66-year-old man was admitted for primary liver cancer, with hypersplenia. On the day of admission, the blood pressure of the patient was 134/76 $\mathrm{mmHg}$, heart rate was $75 \mathrm{bpm}$, respiratory rate was 19 $\mathrm{bpm}$, and oral body temperature was $36.7^{\circ} \mathrm{C}$. Laboratory values were as follows: leukocytes count $5.6 \times 10^{9} / \mathrm{L}$; hemoglobin $12.1 \mathrm{~g} / \mathrm{dL}$; hematocrit $34.8 \%$; platelet count $63 \times 10^{9} / \mathrm{L}$; albumin $2.6 \mathrm{~g} / \mathrm{dL}$; AST $78 \mathrm{IU} / \mathrm{L}$; and ALT $49 \mathrm{IU} / \mathrm{L}$. After RFA, IL-11 was administered subcutaneously at a dose of $3 \mathrm{mg}$ per day because of thrombocytopenia. Two days after the initiation of IL-11, the patient complained of dyspnea with bilateral edema of the feet. On physical examination, his temperature was $36.9^{\circ} \mathrm{C}$, blood pressure was $93 / 59 \mathrm{mmHg}$, and pulse was $92 \mathrm{bpm}$. Fine rales could be heard by auscultation. Shifting dullness was detected in the abdomen. Edema of the hands was also observed (Figure 4). Laboratory values were as follows: leukocytes count $8.9 \times 10^{9} / \mathrm{L}$; hemoglobin $10.7 \mathrm{~g} / \mathrm{dL}$; hematocrit $30.6 \%$; platelet count $51 \times$ $10^{9} / \mathrm{L}$; albumin $1.99 \mathrm{~g} / \mathrm{dL}$. Ascites puncture revealed a few red blood cells in the ascites and the level of albumin in the ascites was $1.3 \mathrm{~g} / \mathrm{dL}$. IL-11 was stopped and human albumin was infused at $10 \mathrm{~g}$ per day. Somatostatin was administered by intravenous push at a dose of $0.25 \mathrm{mg} /$ hour. Platelets and FFP were also infused. On the $4^{\text {th }}$ day after the termination of IL-11, the serum

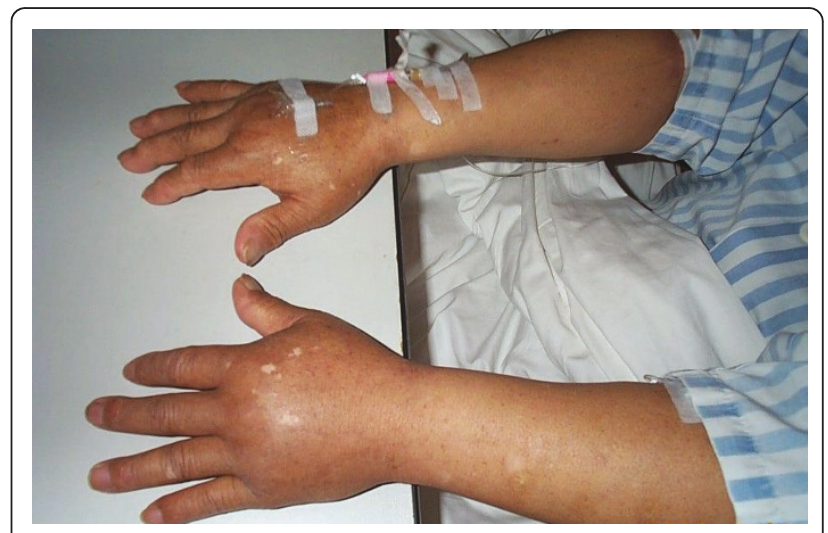

Figure 4 After treatment with IL-11, bilateral edema of the hands were observed in case 2 . 
creatinine $(\mathrm{Cr})$ of the patient was $2.2 \mathrm{mg} / \mathrm{dL}$ (normal range $0.7-1.3 \mathrm{mg} / \mathrm{dL}$ ), and fluid resuscitation was performed after consultation with the urology department. The 24-hour urine volume was $1500-2000 \mathrm{ml}$ after the use of furosemide. Six days after the termination of IL11, the edema of the feet and dyspnea were alleviated. Two weeks after the termination of IL-11, the patient was discharged. The laboratory values were as follows: leukocytes count $4.5 \times 10^{9} / \mathrm{L}$; hemoglobin $10.6 \mathrm{~g} / \mathrm{dL}$; hematocrit 30.2\%; and platelet count $67 \times 10^{9} / \mathrm{L}$. Serum albumin had increased to $3.3 \mathrm{~g} / \mathrm{dL}$.

\section{Conclusions}

IL-11 is a cytokine derived from stromal cells that has multiple effects on thrombocytopenia induced by chemotherapy or bone marrow transplantation (BMT). It was considered to be a safe and well tolerated agent for the treatment of thrombocytopenia after chemotherapy by several clinical trials [13-15]. In addition, IL-11 might be crucial in the acute management of certain types of hypersplenic thrombocytopenia in hepatic carcinoma [16]. Therefore, we choose IL-11 to platelet transfusion, which used to treat thrombocytopenia for preventing life-threatening bleeding episodes in patients with hepatic carcinoma from radiofrequency ablation. The most common side effects of IL- 11 are arthralgias and myalgias, fatigue, nausea, and headache [13]. Mild edema and minor conjunctival bleeding are also associated with the administration of IL-11. The most severe side effects of IL-11 are tachycardia and hypotension, but these seldom occur [14]. To our knowledge, CLS due to the use of IL-11 has never been reported previously, particularly in liver cancer patients.

Herein, we describe two cases of liver cancer patients with anasarca, pleural effusion, and ascites. Clinical and laboratory findings were consistent with an acute episode of CLS. Treatment with hydroxyethyl starch, albumin, and diuretic led to a gradual improvement within 2 weeks. These findings should help to improve the understanding and treatment of this potentially deadly severe side effect of IL-11. Both patients had hypersplenia and elevated levels of ALT and AST, and it seemed likely that these findings were due to the side effects of a drug, such as IL-11, after RFA therapy. The first patient was treated with antibiotics after RFA for prophylaxis against infection because he had a high temperature. However, it became apparent from the subsequent pathogenesis that the symptoms described above were not due to infection, because the patient had hypoalbuminemia and the blood pressure continued to decrease. Some studies have demonstrated that IL-11 can be used in patients not only to promote platelet recovery but also to prevent lifethreatening infections [17].
During the state of shock, hemoconcentration was not observed, but the hematocrit of the patient was decreased. As a consequence, hemorrhage should have been considered in this patient. However, in this patient, the level of hemoglobin and hematocrit increased to normal without the infusion of platelets and hemostasis. The patient did have pleural effusion, ascites and edema in both feet and the scrotum, which were all consistent with CLS, and thus it is likely that the main cause of the observed symptoms was CLS.

It was interesting that hemorrhage was also identified firstly in the second patient. According to some clinical trials, the proportion of hemorrhagic complications after RFA is approximately $1.5 \%$ [18]. Specific treatments, such as blood transfusion and drainage, are required in high-risk patients. However, in the second patient, the level of albumin in the ascites was higher than normal. Hypoalbuminemia and lower blood pressure occurred soon after the initiation of IL-11 and serum Cr was also increased because of hypovolemia. Therefore, the patient was not just a simple hemorrhage, and CLS needed to be considered. Finally, the symptoms of this patient were alleviated by combined treatment with hemostasis and fluid resuscitation, which confirmed that CLS was the main cause of the observed symptoms and hemorrhage might be a secondary reason. There is also the possibility that CLS can be induced by hemorrhage in patients with liver cancer.

The pathogenesis of CLS caused by IL-11 was not elucidated. Some studies have found that vascular endothelial growth factor (VEGF) is associated with CLS $[19,20]$. Furthermore, studies in animal models have shown that the synthesis of nitric oxide (NO) is strongly induced during CLS after cytokine treatment [21]. Another study found that isoforms of NO synthase (NOS), such as endothelial NOS, might play a major role in CLS [22]. Liver pathologies have a negative influence on numerous conditions, including those that affect the endothelial system [23]. In this report, both patients had chronic bleeding after RFA, which indicated that injury of the liver and hypersplenia might be a precipitating factor for CLS.

Further studies are necessary with the objective of collecting sufficient patients with CLS to observe the natural history of the disease and evaluate the efficacy of empiric treatments. These two cases should help to improve the understanding and treatment of the potentially deadly CLS that is related to IL-11 and has been recognized in this study.

\section{Consent statement}

Written informed consent was obtained from the patient for publication of this case report and accompanying 
images. A copy of the written consent is available for review by the Editor-in-Chief of this journal.

\author{
Acknowledgements \\ We acknowledge Dr. Qu Youcun, Dr Wang Xian and Dr. Chen Wei for \\ revising the paper critically; Dr. Lou Fang, Dr Zheng Yu and Dr. Jin Wei for \\ good advise about clinical treatment. This work is support by Zhejiang \\ University Youth Seed Foundation for Interdisciplinary Studies in 2009 and \\ Education Department of Zhejiang Province (Grant number: Y200803847).
}

\section{Authors' contributions}

WKF carried out the patients' therapy, participated in analyzing the state of the two patients and drafted the manuscript. PHM participated in the design of the paper and performed the analysis. LHZ participated in design therapy project, estimate prognosis of the two patients. SLR and ZXY conceived of the study, and participated in its design and coordination. All authors read and approved the final manuscript.

\section{Competing interests}

The authors declare that they have no competing interests.

Received: 20 October 2010 Accepted: 27 May 2011

Published: 27 May 2011

\section{References}

1. Teelucksingh S, Padfield PL, Edwards CR: Systemic capillary leak syndrome. Q J Med 1990, 75:515-524.

2. Matsumura M, Kakuchi Y, Hamano R, Kitajima S, Ueda A, Kawano M, Yamagishi M: ystemic capillary leak syndrome associated with compartment syndrome. Intern Med 2007, 46:1585-1587.

3. Dhir V, Arya V, Malav IC, Suryanarayanan BS, Gupta R, Dey AB: Idiopathic systemic capillary leak syndrome (SCLS): case report and systematic review of cases reported in the last 16 years. Intern Med 2007, 46:899-904

4. Guan H, Nagarkatti PS, Nagarkatti M: Blockade of hyaluronan inhibits IL-2induced vascular leak syndrome and maintains effectiveness of IL-2 treatment for metastatic melanoma. J Immunol 2007, 179:3715-3723.

5. Baron D, Mayo A, Kluger Y: Gemcitabine-induced chronic systemic capillary leak syndrome: a life-threatening disease. Clin Oncol (R Coll Radiol) 2006, 18:90-91.

6. Krzesiński P, Wierzbowski R, Gielerak G, Hałka J, Matysiak O, Smurzyński P: Impedance cardiography in the diagnosis of capillary leak syndrome caused by doxorubicin therapy in a patient with myeloma multiplex. Cardiol I 2010, 17:88-91.

7. Rechner I, Brito-Babapulle F, Fielden J: Systemic capillary leak syndrome after granulocyte colony-stimulating factor (G-CSF). Hematol J 2003, 4:54-56.

8. Yamamoto K, Mizuno M, Tsuji T, Amano T: Capillary leak syndrome after interferon treatment for chronic hepatitis C. Arch Intern Med 2002, 25:481-482.

9. Hsiao SC, Wang MC, Chang H, Pei SN: Recurrent capillary leak syndrome following bortezomib therapy in a patient with relapsed myeloma. Ann Pharmacother 2010, 44:587-589.

10. Abdul-Ghaffar NU, Farghaly MM, Swamy AS: Acute renal failure, compartment syndrome, and systemic capillary leak syndrome complicating carbon monoxide poisoning. J Toxicol Clin Toxicol 1996, 34:713-719.

11. Kanda K, Sari A, Nagai K, Matayoshi Y: Postpartum capillary leak syndrome. A case report. Crit Care Med 1980, 8:661-662.

12. Handfield-Jones SE, Garvey M, McGibbon DH, Black MM: Capillary leak syndrome in generalized pustular psoriasis. Br J Dermatol 1992, 127:64.

13. Gordon MS, McCaskill-Stevens WJ, Battiato LA, Loewy J, Loesch D, Breeden E, Hoffman R, Beach KJ, Kuca B, Kaye J, Sledge GW Jr: A phase I trial of recombinant human interleukin-11 (neumega rhIL-11 growth factor) in women with breast cancer receiving chemotherapy. Blood 1996, 87:3615-3624.

14. Vredenburgh JJ, Hussein A, Fisher D, Hoffman M, Elkordy M, Rubin P, Gilbert C, Kaye JA, Dykstra K, Loewy J, Peters WP: A randomized trial of recombinant human interleukin-11 following autologous bone marrow transplantation with peripheral blood progenitor cell support in patients with breast cancer. Biol Blood Marrow Transplant 1998, 4:134-141.

15. Giles FJ, Kantarjian HM, Cortes JE, Faderl S, Verstovsek S, Thomas D, GarciaManero G, Wierda W, Ferrajoli A, Kornblau S, Mattiuzzi GN, Tsimberidou AM, Albitar M, O'Brien SM, Estey E: Adaptive randomized study of idarubicin and cytarabine alone or with interleukin-11 as induction therapy in patients aged 50 or above with acute myeloid leukemia or high-risk myelodysplastic syndromes. Leuk Res 2005, 29:649-652.

16. Ustun C, Dainer PM, Faguet GB: Interleukin-11 administration normalizes the platelet count in a hypersplenic cirrhotic patient. Ann Hematol 2002, 81(10):609-610.

17. Teramura M, Kobayashi S, Yoshinaga K, Iwabe K, Mizoguchi H: Effect of interleukin 11 on normal and pathological thrombopoiesis. Cancer Chemother Pharmacol 1996, 38:S99-102.

18. Goto E, Tateishi R, Shiina S, Masuzaki R, Enooku K, Sato T, Ohki T, Kondo Y, Goto T, Yoshida H, Omata M: Hemorrhagic complications of percutaneous radiofrequency ablation for liver tumors. J Clin Gastroenterol 2010, 44:374-380.

19. Lesterhuis WJ, Rennings AJ, Leenders WP, Nooteboom A, Punt CJ, Sweep FC, Pickkers P, Geurts-Moespot A, Van Laarhoven HW, Van der Vlag J, Berden JH, Postma CT, Van der Meer JW: Vascular endothelial growth factor in systemic capillary leak syndrome. Am J Med 2009, 122: e5-7.

20. Kinoshita Y, Kasaoka S, Fujita M, Oshima C, Kawamura Y, Tsuruta R, Maekawa T: Synchronized changes in serum vascular endothelial growth factor during the clinical course of chronic systemic capillary leak syndrome. Intern Med 2010, 49:791-794.

21. Timoshenko AV, Lan Y, Gabius HJ, Lala PK: Immunotherapy of C3H/HeJ mammary adenocarcinoma with interleukin-2, mistletoe lectin or their combination. effects on tumour growth, capillary leakage and nitric oxide (NO) production. Eur J Cancer 2001, 37:1910-1920.

22. Kondapaneni M, McGregor JR, Salvemini D, Laubach VE, Samlowski WE: Inducible nitric oxide synthase (iNOS) is not required for IL-2-induced hypotension and vascular leak syndrome in mice. J Immunother 2008, 31:325-333.

23. Druey KM, Greipp PR: Narrative review: the systemic capillary leak syndrome. Ann Intern Med 2010, 153:90-98.

\section{Pre-publication history}

The pre-publication history for this paper can be accessed here: http://www.biomedcentral.com/1471-2407/11/204/prepub

\section{doi:10.1186/1471-2407-11-204}

Cite this article as: Kai-Feng et al: Interleukin-11-induced capillary leak syndrome in primary hepatic carcinoma patients with thrombocytopenia. BMC Cancer 2011 11:204.

\section{Submit your next manuscript to BioMed Central and take full advantage of:}

- Convenient online submission

- Thorough peer review

- No space constraints or color figure charges

- Immediate publication on acceptance

- Inclusion in PubMed, CAS, Scopus and Google Scholar

- Research which is freely available for redistribution

Submit your manuscript at www.biomedcentral.com/submit
C Biomed Central 